\title{
A EDUCAÇÃO A DISTÂNCIA NAS ORGANIZAÇÕES: A PERCEPÇÃO SOBRE O E-LEARNING EM UMA GRANDE EMPRESA NACIONAL
}

\author{
André Ferreira | andre.ferreira10@gmail.com \\ Professor Assistente - Gestão de Pessoas, do Departamento de Administração de Empresas de Volta Redonda da Universidade Federal \\ Fluminense.
}

Juliana Nogarect da Silva Valério | ju.valerio@yahoo.com.br

Graduada em Administração pela Universidade Federal Fluminense.

Gustavo Costa Souza | gustavocosta@gmail.com

Professor Assistente da UFRRJ, do curso de Administração de Empresas.

\section{Resumo}

Este artigo busca verificar a percepção dos funcionários de um grande banco nacional sobre a eficácia do elearning como ferramenta de aprendizagem, abordando aspectos relacionados à utilização dos recursos de informática, autodisciplina, instrutor em tempo integral, nível de aprendizado dos cursos e-learning, interatividade e qualidade gráfica, vantagem de determinar o horário de estudo, relação entre os cursos e-learning e as competências essenciais da empresa, aplicabilidade dos temas e a percepção dos correspondentes se o e-learning é uma tendência ou moda passageira. Os resultados indicam que, de forma geral, a aceitação da metodologia e-learning é bastante positiva por parte dos funcionários desta organização financeira e apontam para a necessidade de novos estudos que analisem a diferença do nível de aprendizagem entre cursos e-learning e cursos presenciais, formas de compensar a ausência de contato permanente entre instrutor $e$ aluno no decorrer do curso $e$ fatores que determinam a disciplina dos participantes para realização das atividades de e-learning.

\section{Palavras-chave}

Educação a Distância. Treinamento. E-learning. Universidade corporativa. 
DISTANCE EDUCATION IN ORGANIZATIONS: PERCEPTIONS OF E-LEARNING IN A LARGE NATIONAL COMPANY

\section{Abstract}

This article seeks to ascertain how employees of a large national bank perceive the effectiveness of $e$ learning as a learning tool, addressing issues related to the use of IT resources, self-discipline, full-time instructors, the learning level of e-learning courses, interactivity and graphic quality, the advantages of determining study time, relationship between e-learning courses and the company's core competencies, the applicability of themes and respondents' perception of whether e-learning is a trend or a fad. The results indicate that, overall, e-learning methodology is well accepted by this financial organization's employees, and call for further studies to examine the difference in learning levels between e-learning courses and classroom courses, ways to compensate for the lack of permanent contact between instructor and student during the course, and the factors governing participants' discipline in performing e-learning activities.

\section{Keywords}

Distance education. Training. E-learning. Corporate university.

\section{Introdução}

Há poucos anos, a percepção dos indivíduos em relação aos cursos realizados a distância não era positiva, e a opinião dominante era que a qualidade dessa metodologia deixava a desejar. Esse cenário tem mudando significativamente, apontando para um caminho diametralmente oposto, onde empresas, universidades e governo têm investido cada vez mais na Educação a Distância (EAD). No mundo corportativo, o avanço da EAD é percebido através da difusão do e-learning como uma ferramenta importante para o desenvolvimento da Educação Corporativa e os principais motivos para esse avanço estão relacionados aos avanços em informática e telecomunicações; além disso, os treinandos e as organizações têm necessidades de aprendizagem que podem ser atendidas pelo e-learning.
No caso dos treinandos, as crianças e os adolescentes de hoje, que em breve estarão dentro das organizações, já experimentam a interação com informações e conhecimentos através do computador $e$ da internet; Assim, será que eles se sentirão estimulados a aprender da forma como aprendemos hoje? (SOELTL, 2002). A resposta provável é não, pois a popularização do uso da informática e dos recursos da internet no Brasil, que cresce a cada ano, tende a se tornar ainda maior. Com isso, essa transição no processo de aprendizagem, onde os alunos passam a utilizar com maior frequência a Educação a Distância (EAD) baseada em tecnologia, pode representar uma ruptura nos dias de hoje, mas em médio prazo deverá ser uma exigência do mercado, ou seja, os próprios treinandos irão demandar um sistema de ensino adaptado às suas experiências e necessidades, fortemente marcadas pela familiaridade com a informática tanto para questões de ensino quanto para questões profissionais ou de lazer.

Pelo lado das organizações, a necessidade de utilizar o e-learning está calcada principalmente na rapidez com que os mercados mudam, exigindo delas respostas ágeis e eficazes. Nesse caso, o e-learning pode prestar contribuições importantes na preparação dos recursos humanos das organizações para enfrentar esses desafios, pois em determinados pontos, apresenta vantagens importantes sobre os tradicionais treinamentos presenciais, com destaque para a rapidez na difusão de conhecimentos e informações, a facilidade para atingir um número maior de participantes e a possibilidade de atualização rápida de seu conteúdo. Assim sendo, a previsão é que, da mesma forma que o e-mail, o aprendizado através da internet é um fenômeno que tende a se incorporar à nossa vida rapidamente (SOELTL, 2002).

Mas ainda existem barreiras importantes que necessitam ser transpostas para a plena implantação do $e$ learning. Talvez a mais significativa seja a resistência à $\mathrm{EAD}$, pois até pouco tempo ela era vista como um ensino de segunda linha (PILLA, NAKAYAMA e BINOTTO, 2006) e ainda enfrenta certa desconfiança no Brasil, pois muitos ainda creem que a qualidade de um curso depende da presença física do professor (LAGO e SANTOS, 2005). Uma referência a essa 
crença é o ditado popular que diz que quando alguém é considerado incompetente, é porque tirou o diploma por correspondência. Essa barreira à EAD poderá estar definitivamente superada quando os alunos tiverem a percepção de que o nível de aprendizagem de um curso a distância é, no mínimo, equivalente ao nível de aprendizagem de um curso presencial. É importante ressaltar que o e-learning pode contribuir de forma significativa para essa mudança de percepção dos treinandos sobre a EAD.

Se a credibilidade é a maior barreira por parte dos treinandos, para as organizações as principais limitações são, conforme pesquisa realizada pelo site e-learningbrasil.com.br (apud LEMOS, 2003): investimento em software, investimento em administração, nível de preparo dos funcionários, investimento em infraestrutura e custos com consultoria. Observase que as barreiras são distintas, pois enquanto os treinandos estão preocupados com a qualidade do aprendizado proporcionado pelos cursos e-learning, as organizações têm um foco maior sob os custos referentes à sua implantação.

Outra consideração a ser feita acerca da resistência a essa modalidade de ensino é a transformação no papel do aluno que a EAD requer. Trata-se de uma transformação importante em termos culturais, pois nos processos de Educação a Distância é o aluno quem assume a função central no processo de aprendizagem. Diferente das modalidades tradicionais de ensino, em que o professor assume a responsabilidade de transmitir o conhecimento para os alunos, na EAD é o aluno quem constrói o seu próprio aprendizado. Sendo assim, é uma modalidade baseada na disciplina, no autodidatismo. Essa transformação do papel do aluno de receptor/depositário do conhecimento (FREIRE, 1996) para uma postura mais proativa no sentido de se buscar o conhecimento envolve um esforço grande em termos de mudança de comportamento, fator este reforçado pelo fato que os alunos, sendo já adultos, desde a infância foram socializados a partir de modelos de ensino tradicional.

Neste contexto, o objetivo desse trabalho é dar continuidade à pesquisa iniciada em 2007 para investigar a percepção dos usuários do e-learning no que concerne à facilidade para utilização dos recursos de informáti- ca, autodisciplina para realizar o curso, relação entre ausência do instrutor em tempo integral e qualidade do curso, comparação do nível de aprendizado dos cursos e-learning em relação aos cursos presenciais, apresentação gráfica e nível de interação dos cursos, vantagem de determinar o horário de estudo, relação entre os cursos e-learning e as competências essenciais, aplicabilidade dos temas abordados e percepção se o e-learning é uma tendência na educação corporativa ou apenas uma moda passageira.

A primeira pesquisa foi realizada na Sul América Seguros e contou com a participação de 87 funcionários. Nessa segunda rodada a pesquisa foi realizada junto a 90 funcionários de um dos maiores bancos de varejo do Brasil, que possui, assim como a SulAmérica, um longo histórico de utilização da EAD. Neste artigo serão apresentados os resultados da pesquisa nessa instituição financeira. Posteriormente, novos trabalhos serão realizados para uma análise comparativa dos dados das duas pesquisas.

A seguir é apresentada a revisão bibliográfica, que aborda questões sobre a aprendizagem, o e-learning, a evolução tecnológica $e$ as universidades corporativas.

\section{Revisão bibliográfica}

\subsection{Breve consideração sobre a aprendizagem e o e-learning}

A aprendizagem pode ser entendida como um processo de mudança provocado por estímulos diversos e mediado por emoções que podem ou não produzir mudança no comportamento da pessoa (FLEURY, 2002). Complementando esse conceito, Peter Senge (apud ROSENBERG, 2006) afirma que aprendizagem é um fenômeno complicado, que jamais pode ser limitado a uma sala de aula e também não deve ser confundido com treinamento.

Essas definições remetem a uma análise etimológica da palavra e-learning, que em uma tradução literal para o português seria algo como e-aprendizagem. A partir dessa abordagem é possível estabelecer uma dimensão mais ampla do e-learning, que não se limita somente a ser um substituto para os treinamentos em sala de aula, pois se assim fosse sua denominação correta deveria ser e-training (ROSENBERG, 2006). Essa distinção é importante, pois considerar o e-learning em um sentido 
mais restrito pode bloquear seu desenvolvimento através dos paradigmas de treinamento. Dublin (2006) descreve bem essa possibilidade quando narra o caso de um treinando que acessa um curso online, procura no índice o módulo que lhe interessa, consulta e encontra as respostas corretas para suas dúvidas, realiza logoff $e$ aplica o que acabou de aprender. Isso pode ser considerado aprendizagem, mas para o sistema de gerenciamento do treinamento isso é uma falha, ou uma evasão de curso, e dessa forma vai empreender ações visando corrigir esse falso problema. Do mesmo modo, um treinamento e-learning que não permite o retorno ao curso após o seu encerramento também significa uma chance desperdiçada de se quebrar esses paradigmas, pois se o treinamento tem hora para começar e acabar, a aprendizagem, de forma distinta, pode e deve acontecer em qualquer lugar e a qualquer momento.

\subsection{Do ensino a distância ao e-learning}

\section{através da evolução tecnológica}

Na Educação a Distância (EAD), o cerne da metodologia é a separação física entre o instrutor e o treinando durante a maior parte do processo instrucional, mas comumente envolve algum tipo de atividade que reduza a sensação de isolamento do aluno (LEMOS, 2003). Para Farias (2004) um curso a distância só pode ser assim definido quando, além do conteúdo e planejamento de estudo, vem acompanhado de recursos interativos, que permitam a comunicação sistemática entre aluno e tutor. Ainda segundo Farias, cursos oferecidos em revistas acompanhadas por $\mathrm{CD}$, ou em tutoriais disponíveis na internet, não são cursos a distância, e podem ser definidos apenas como estudos dirigidos.

A popularização da EAD nos últimos anos deve-se muito à evolução da tecnologia da informação, principalmente da informática, e das comunicações, que possibilitou o surgimento de uma nova modalidade de $\mathrm{EAD}$, o e-learning, que é fortemente baseado em tecnologia, permitindo eliminar algumas limitações bastante conhecidas da $\mathrm{EAD}$, tais como a falta de interatividade, evasão de alunos, conteúdos fracos, materiais didáticos pouco atraentes e ausência da verificação do nível de aprendizagem (LEMOS, 2003).

Dessa forma, segundo Rosenberg (apud, FLEURY, 2003), o e-learning pode ser considerado uma modali- dade de $\mathrm{EAD}$ e se refere ao uso de tecnologias de internet para disponibilizar um amplo leque de soluções que buscam melhoria de conhecimento e performance.

Assim como os antigos cursos de EAD, o e-learning, no que se refere à simultaneidade das atividades, pode ser dividido em dois tipos de modalidade (SOELTL, 2002):

- Modalidade assíncrona: participantes realizam atividades em dia e horário de sua conveniência, independentemente da presença do professor ou instrutor e dos demais integrantes da turma.

- Modalidade síncrona: os participantes e os instrutores têm dia e horário determinados para realizar as atividades de forma presencial ou virtual, através de videoconferência, audioconferência, fórum ou chat.

Experiências bem-sucedidas em EAD normalmente utilizam as duas modalidades, compondo atividades assíncronas, a fim de proporcionar flexibilidade, $e$ atividades síncronas, que propiciam maior interação entre alunos e tutores. Essas modalidades de interação tiveram um salto qualitativo a partir da evolução da tecnologia, que facilitou a interatividade entre treinandos $e$ instrutores separados geograficamente, bem como permitiu o acesso rápido a materiais educativos de forma não linear e interativa (LEMOS, 2003).

Mas, apesar dos recursos da tecnologia, que permitem, dentre outras coisas, armazenamento e compartilhamento de informações, comunicação rápida através do e-mail, realização de reuniões interativas via chat, impressão e pesquisa na web, observase, por outro lado, que os recursos de informática e comunicação menos dominados pelos treinandos (recursos de áudio e vídeo e ferramentas de chat e fórum) referem-se justamente às ferramentas que permitem a redução da distância espacial e temporal entre aluno $e$ instrutor (ZERBINI, NASCIMENTO, MENESES et. al, 2006).

Esse é um indicativo de que as organizações necessitam avaliar o nível de conhecimento de informática de seus colaboradores, principalmente nos recursos já citados, provendo capacitação visando garantir a plena utilização dos recursos das facilidades proporcionadas pela tecnologia para a realização de cursos e-learning. 
Independentemente das dificuldades ainda encontradas por parte dos treinandos para dominar determinados comandos de seus sistemas informáticos e de comunicação, a flexibilidade de acesso que essas novas tecnologias proporcionam aos cursos e-learning é considerada como uma das principais vantagens para os treinandos, pelo fato de não terem de cumprir horários predeterminados, nem se deslocar todos os dias, podendo assim aproveitar melhor seu tempo e obter maior aproveitamento do curso (LAGO;SANTOS, 2005). Dessa forma, o fato de poder determinar o horário em que irá estudar pode representar para o treinando uma grande vantagem dos cursos e-learning em relação aos cursos presenciais.
Os benefícios do e-learning também se estendem às organizações, que segundo Rosenberg $(2006,47)$, através do e-learning podem alcançar pessoas que estão dispersas geograficamente, permite um grande número de participantes, melhora a eficiência do treinamento permitindo que mais informações possam ser entregues para mais pessoas e a custo baixo, permite atualização rápida dos conteúdos dos treinamentos e finalmente pode se usado para monitorar os resultados do treinamento, provendo um feedback e coaching de alta qualidade, que em alguns casos podem ser mais valiosos do que o curso propriamente dito.

Complementando as considerações de Rosenberg, Fleury e Jacobsohn (2003), a partir de uma revisão bibliográfica, elaboraram um resumo dos principais benefícios e também as principais limitações do e-learning, tanto para as organizações quanto para os trei-

Quadro 1: Benefícios e limitações do e-learning

\begin{tabular}{|c|c|c|}
\hline Categoria & Benefícios & Limitações \\
\hline $\begin{array}{l}\text { Recursos } \\
\text { financeiros }\end{array}$ & $\begin{array}{l}\text { - Redução de custos de viagens, de tempo de } \\
\text { deslocamento e de infraestrutura } \\
\text { - Aumento do } n^{\circ} \text { de alunos com baixo custo } \\
\text { incremental }\end{array}$ & $\begin{array}{l}\text { - Alto investimento inicial } \\
\text { - Investimento em equipamentos } \\
\text { - Estrutura para atendimento ao aluno }\end{array}$ \\
\hline $\begin{array}{l}\text { Gestão do } \\
\text { curso }\end{array}$ & $\begin{array}{l}\text { - Uniformidade e consistência na mensagem } \\
\text { - Informações mais completas } \\
\text { - Facilidade e rapidez para atualização } \\
\text { - Estruturas curriculares mais flexíveis } \\
\text { - Treinamento de grande número de alunos } \\
\text { simultaneamente }\end{array}$ & $\begin{array}{l}\text { - Alto investimento inicial } \\
\text { - Investimento em equipamentos } \\
\text { - Estrutura para atendimento ao aluno }\end{array}$ \\
\hline $\begin{array}{l}\text { Dinâmica do } \\
\text { grupo }\end{array}$ & $\begin{array}{l}\text { - Integração de pessoas distantes } \\
\text { geograficamente } \\
\text { - Construção de comunidades virtuais }\end{array}$ & $\begin{array}{l}\text { - Perda do aspecto social do aprendizado } \\
\text { - Sentimento de isolamento } \\
\text { - Impacto na cultura }\end{array}$ \\
\hline Aluno & $\begin{array}{l}\text { - Ritmo do curso adaptado ao aluno } \\
\text { - Acesso de qualquer lugar e a qualquer hora } \\
\text { - Postura ativa frente ao próprio processo de } \\
\text { aprendizagem } \\
\text { - Maior participação do aluno }\end{array}$ & $\begin{array}{l}\text { - Dificuldade de leitura e interpretação de textos } \\
\text { - Manutenção da postura passiva } \\
\text { - Dificuldade para usar a tecnologia } \\
\text { - Baixa velocidade de digitação }\end{array}$ \\
\hline
\end{tabular}

Fonte: Fleury e Jacobsohn, 2003, p. 8.

nandos, dividindo-os em quatros categorias: recursos financeiros, gestão do curso, dinâmica de grupo e de aluno, conforme descrito no Quadro 1:

A identificação das limitações do e-learning é fundamental, pois, segundo Eboli (apud LEMOS, 2003) as vantagens do e-learning são tão sedutoras - como por exemplo, aprender mais, melhor e mais rápido e assim se tornar mais inteligentes e competentes - que, muitas vezes, essas vantagens se tornam um fim em si mesmas, ou seja, desenvolve-se um programa de e-learning sem antes ter uma visão clara das necessidades de aprendizagem da organização.

Outra barreira ao desenvolvimento do e-learning comumente encontrada é o medo de subs- 
tituição, quando profissionais de treinamento temem perder seus empregos (LEMOS, 2003). $\mathrm{Na}$ verdade, o e-learning complementa a sala de aula, mas não a substitui. Provavelmente a quantidade de horas em sala de aula será menor, mas o volume de aproveitamento e as experiências vivenciadas serão maiores. Deve-se considerar também que os treinamentos presenciais têm diversos benefícios, com destaque para a rapidez no desenvolvimento e entrega, especialmente para um número pequeno de pessoas, possibilita grandes oportunidades de trabalho em equipe, resolução de problemas em grupo e cria vínculo entre os participantes. Isso demonstra que, apesar de algumas limitações, o treinamento presencial permanece uma poderosa ferramenta para a aprendizagem (ROSENBERG, 2006).

No Brasil, o e-learning começou um tanto tímido em meados dos anos de 1990, mas hoje apresenta um ritmo acelerado de crescimento (LAGO; SANTOS, 2005). Essa expansão permitiu criar um grau de maturidade e experiência que pode servir como referência para o desenvolvimento e aprimoramento do elearning no país. O Quadro 2 apresenta um resumo

Quadro 2: Lições aprendidas

\begin{tabular}{|l|l|}
\hline $\begin{array}{l}\text { 1. Alinhamento } \\
\text { com a estratégia }\end{array}$ & $\begin{array}{l}\text { O sucesso de uma iniciativa de e-learning está diretamente ligado ao atendimento dos } \\
\text { objetivos estratégicos da organização. }\end{array}$ \\
\hline $\begin{array}{l}\text { 2. Avaliação de } \\
\text { resultados }\end{array}$ & $\begin{array}{l}\text { É fundamental estabelecer um processo efetivo para avaliação dos resultados, visando } \\
\text { garantir que o e-learning está sendo utilizado para melhorar o desempenho das pessoas e } \\
\text { das organizações. }\end{array}$ \\
\hline $\begin{array}{l}\text { 3. Foco na } \\
\text { pedagogia, não na } \\
\text { tecnologia }\end{array}$ & $\begin{array}{l}\text { Na abordagem presencial, elementos como proximidade do aluno, nível de desempenho } \\
\text { e conhecimento do instrutor, material de apoio e infraestrutura do ambiente são } \\
\text { determinantes. No aprendizado e-learning, esses elementos perdem seu efeito e novos } \\
\text { elementos como design instrucional, planejamento de atividades síncronas e assíncronas, } \\
\text { grupais e individuais, atividades tutoriais e avaliações ganham importância. }\end{array}$ \\
\hline $\begin{array}{l}\text { 4. Importância da } \\
\text { metodologia e da } \\
\text { gestão de mudança }\end{array}$ & $\begin{array}{l}\text { O fator fundamental de um projeto e-learning é o fator humano. A aceitação desse novo } \\
\text { formato pelas pessoas é fundamental. Dessa forma, é necessário utilizar uma metodologia } \\
\text { que promova uma comunicação clara, estabelecendo-se papéis e responsabilidades. }\end{array}$ \\
\hline $\begin{array}{l}\text { 5. Apoio ao projeto } \\
\text { e ao aluno }\end{array}$ & $\begin{array}{l}\text { A sensação de solidão é um grande risco para o sucesso da implementação do e-learning. } \\
\text { Estruturas de assistência, na figura do monitor e tutor, ajudam a estabelecer um canal de } \\
\text { relacionamento e apoio aos usuários. }\end{array}$ \\
\hline
\end{tabular}

Fonte: adaptado da revista T\&D, 2005, p. 41.

das 5 principais lições aprendidas pelas empresas que participaram do Prêmio e-learning Brasil no período de 2002 a 2004 (REVISTA T\&D, 2005).

Em síntese, das lições aprendidas pelas organizações pode-se ressaltar alguns termos - chaves nesse processo, tais como: alinhamento com a estratégia, importância de avaliar resultados, não ter a tecnologia como ponto central do processo e necessidade de se prestar suporte total aos treinandos.

Conforme citado anteriormente, o aprendizado através da internet é um fenômeno que vai se in- corporar à nossa vida rapidamente e um dos motivos dessa rápida incorporação, principalmente dentro das grandes organizações, está relacionado com o processo de transição dos tradicionais centros de treinamento para uma nova forma de educação, denominada Universidade Corporativa ou Educação Corporativa, que, para Eboli (2004a), são termos equivalentes.

Ainda segundo Eboli (apud LEMOS, 2003) as experiências mais bem-sucedidas de Universidades Corporativas estão fundamentadas na Educação a Distância 
e na utilização intensiva da tecnologia. Dessa forma, para complementar essa revisão bibliográfica, o tema Universidade Corporativa é abordado a seguir.

\subsection{Universidade Corporativa, a estratégia e o e-learning}

Os investimentos em ações de Treinamento \& Desenvolvimento sempre foram vultosos, principalmente em programas de treinamento presenciais (SALAS \& CANNON-BOWERS apud ZERBINI, NASCIMENTO, MENESES et al., 2006), mas pouco retorno, em termos de melhorias de desempenho organizacional, era obtido por meio de tais ações. Para Eboli (apud FILHO e DIAS, 2006), o principal motivo desse baixo retorno no Brasil é o fato de que a maioria dos programas de treinamento aplicados ainda continua desvinculada das estratégias do negócio, agregando pouco valor aos resultados obtidos, embora os gastos com esses programas sejam bastante significativos também no Brasil.

Ainda segundo Eboli, o surgimento do conceito de Universidade Corporativa (UC) representou o divisor de águas, um marco histórico que evidencia a passagem do centro de treinamento tradicional, que possui foco nos cargos, para a educação corporativa, com foco nas competências e abrangendo não só os funcionários, mas também os parceiros da empresa.

Segundo Meister (1999) Universidade Corporativa é um "guarda-chuva" estratégico para desenvolver e educar funcionários, clientes, fornecedores e comunidade, a fim de cumprir as estratégias empresariais da organização. Ferraz (2002) complementa este conceito ao considerar as Universidades Corporativas como entidades que se assemelham mais a instituições de ensino que a estruturas e departamentos das empresas e que seu maior mérito está em garantir o processo de aprendizagem constante das organizações pelo aporte de novos conhecimentos, tornando explícito o saber tácito que permeia a organização.

Os dois conceitos apresentados enfatizam questões relacionadas à estratégia, educação permanente e a participação de funcionários, clientes, fornecedores e comunidade. Além disso, segundo Meister (1998, 4):

(...) as Universidades Corporativas estão buscando pioneiramente novas formas criativas de ensinar gerentes o perfil que eles necessitam para atuarem em uma economia baseada no conhecimento. Elas estão reinventando o que era chamado de "treinamento" e dentro deste processo estão a educação para aumentar sua proximidade coma s estratégias de negócios das corporações. A tendência agora é o contrário do velho ditado "Aquele que não sabe fazer ensina" - por que aqueles que fazem, agora também estão ensinando e consequentemente também aprendendo.

A questão da importância da experiência prática no processo de ensino também é compartilhada por Ferraz (2002) para quem na educação profissional, aprender com quem faz, ou já fez, é imperativo.

Esta talvez seja uma das principais diferenças entre as Universidades Tradicionais, fundamentadas fortemente na pesquisa científica e na geração do conhecimento, e as Universidades Corporativas, que buscam respostas aos enormes desafios que as organizações se deparam não somente no conhecimento teórico gerado pelas Universidades Tradicionais, mas também no conhecimento prático de quem efetivamente faz.

As Universidades Corporativas utilizam como ponto de sustentação modelos estratégicos de gestão de pessoas (FILHO e DIAS, 2006) e para Eboli $(2005,119)$ :

(...) Conceber o projeto de Educação Corporativa a partir do plano estratégico de negócios é o que realmente diferencia o Sistema de Educação Corporativa de um Centro de Treinamento Tradicional. Para tanto, são fundamentais quatro pontos: obter o comprometimento e envolvimento da alta cúpula, alinhar o modelo de gestão de pessoas às estratégias do negócio, implantar um modelo de gestão de pessoas por competências e conceber programas educacionais alinhados às estratégias do negócio. Um número crescente de CLOs está se reportando hoje diretamente ao CEO para estabelecer as direções que devem ser seguidas na área de educação.

As competências ocupam também um papel destaque nas UCs. Ainda segundo Eboli (apud CARVALHO, 2001) o principal objetivo da universidade corporativa é o desenvolvimento e a instalação das competências profissionais, técnicas e gerenciais consideradas essenciais para a viabilização das estratégias da organização.

O conceito de competências essenciais foi difundido por Hamel e Prahalad (1990, 4):

No curto prazo, a competitividade de uma empresa deriva dos atributos preço/ performance dos produtos existentes... e no longo 
prazo a competitividade deriva da habilidade de construir, com custos mais baixos e mais rapidamente que os concorrentes, as competências essenciais que geram produtos e serviços que não podem se antecipados pela concorrência. A real fonte de vantagens é encontrada nas habilidades de gerenciamento que são usadas para transformar as tecnologias e a organização do trabalho em competências que preparam uma organização para se adaptar rapidamente às mudanças...

Em termos estratégicos, as competências essenciais das organizações são desdobradas em competências funcionais para todos os níveis da organização. Neste contexto, a Universidade Corporativa tem amplo espaço para atuar visando capacitar os funcionários no atingimento de suas competências individuais, que contribuirão para consolidação das competências funcionais e consequentemente competências essenciais corporativas.

Além do vínculo com a estratégia e o desenvolvimento de competências essenciais, outra característica importante das Universidades Corporativas é o uso intensivo da metodologia de treinamento e-learning $e$, segundo pesquisa da ABRH (apud SOELTL, 2002), as principais razões de negócio que direcionaram as empresas para a adoção do e-learning foram:

- Redução de custos de viagem: 69\%;

- Novas oportunidades e negócio: 66\%;

- Redução de custos de treinamento: $62 \%$;

- Agilizar o lançamento de novos produtos: $58 \%$;

- Aumento da produtividade de processos: $56 \%$;

- Melhor utilização dos produtos atuais pelos clientes: $55 \%$;

- Permanência dos especialistas nos postos de trabalho: 50\%;

- Maior envolvimento de parceiros e fornecedores: $50 \%$.

Não se dispõem do número exato de organizações efetivamente engajadas em atividades de Educação Corporativa, mas, por indicações diversas - em 2006 este número estaria entre 100 e 150 Universidades Corporativas (FERREIRA, 2006) (EBOLI, 2005). São organizações brasileiras ou multinacionais, tanto na esfera pública quanto na privada, que já implantaram e estão operando seus sistemas de educação corporativa.

Para finalizar a caracterização das Universidades Corporativas, Eboli (2004b) considera que as expe- riências bem-sucedidas de Educação Corporativa são aquelas que realizam parcerias com as universidades, pois estas têm competência para agregar valor aos programas de desenvolvimento das empresas.

A revisão bibliográfica estabeleceu os parâmetros para realização da pesquisa, que tem sua metodologia descrita a seguir.

\section{Metodologia}

Em função das características da presente pesquisa, foi escolhido o método de estudo de caso para atingir os objetivos propostos. Para Yin (2005), estudo de caso é apenas uma das muitas maneiras de fazer pesquisa em ciências sociais e, no geral, esta metodologia é a preferida quando o pesquisador tem pouco controle sobre os acontecimentos e quando o foco se encontra em fenômenos contemporâneos inseridos em algum contexto da vida real. O tema e-learning é caracterizado como contemporâneo e em processo de inserção nas grandes organizações brasileiras.

\subsection{A empresa pesquisada}

O estudo de caso será conduzido em uma grande organização financeira, com presença em todo território nacional. Com mais de 100 anos de existência, uma das características desta organização é sua política de gestão de pessoas, com forte investimento no desenvolvimento de seus funcionários e alinhada aos objetivos estratégicos.

A escolha da empresa se justifica pela ampla utilização de cursos de ensino a distância e a implantação de sua Universidade Corporativa fortemente ancorada em cursos e-learning.

\subsection{A pesquisa}

O estudo sobre a percepção dos empregados desta instituição financeira em relação aos cursos e-learning, foi realizada através de pesquisa exploratória, no mês de junho e julho de 2008. A coleta de dados foi feita através de questionários impressos, que foram distribuídos pessoalmente aos participantes.

A pesquisa foi realizada com ocupantes de cargos técnicos, administrativos e gerenciais de agências bancárias nos estados do Rio de Janeiro, São Paulo e Minas Gerais. Foram distribuídos formulários para 
150 funcionários, sendo que o critério de distribuição utilizado foi o de conveniência de acesso e foram retornados 90 questionários, o que representa uma taxa $60 \%$.

O questionário é composto de afirmativas relacionadas ao e-learning, elaboradas após a revisão bibliográfica e que exploram: a percepção dos correspondentes sobre o nível de concordância com temas relacionados à facilidade para utilização dos recursos de informática, autodisciplina para realizar o curso; relação entre ausência do instrutor em tempo integral e a qualidade do curso; comparação do nível de aprendizado dos cursos e-learning em relação aos cursos presenciais; apresentação gráfica e nível de interação dos cursos; vantagem de determinar o horário de estudo; relação entre os cursos e-learning e as competências essênciais; aplicabilidade dos temas abordados; e a percepção se o e-learning é uma tendência ou moda passageira.
As respostas para cada afirmativa estão dispostas em uma escala Likert, hierarquizadas de 1 a 4, sendo: 1- Discordo completamente; 2- Discordo; 3- Concordo; e 4- Concordo plenamente.

\section{Análise dos resultados}

\subsection{Pesquisa explanatória}

A amostra, constituída de 90 funcionários, sendo $52 \%$ do sexo masculino, possui média de idade de 35 anos, $41 \%$ dos respondentes está situado na faixa etária entre 20 e 29 anos e $30 \%$ entre 30 e 39 anos. O tempo médio de empresa é de 8 anos e, no aspecto escolaridade, predominam os participantes com nível superior completo, com $66 \%$ da amostra. Um dado relevante é que $71 \%$ dos participantes já realizaram 31 horas ou mais de cursos e-learning, o que retrata o esforço dessa organização na difusão desta metodologia, conforme demonstrado no Gráfico 1.

Gráfico 1: Horas de treinamento e-learning.

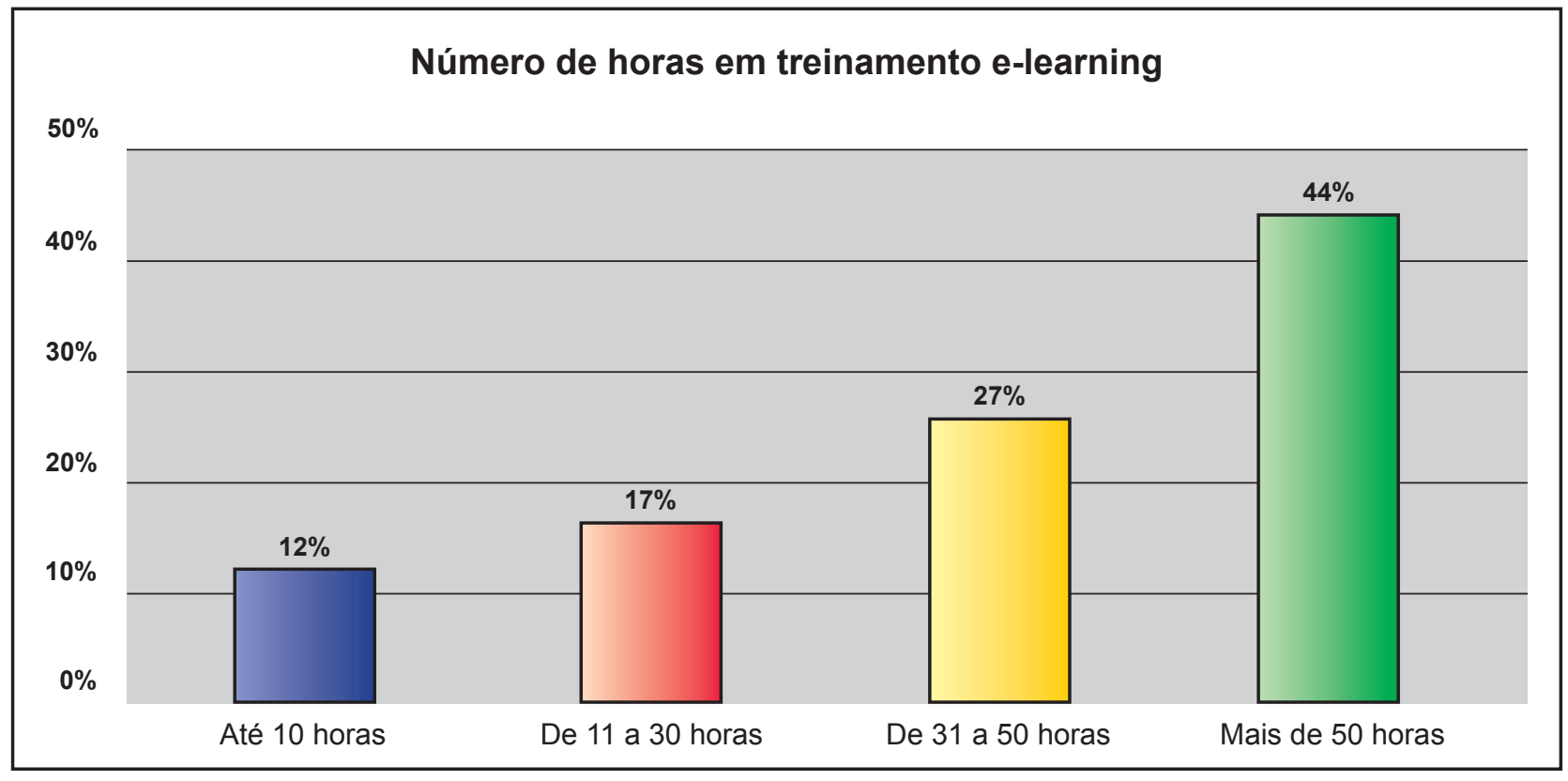

Dos nove aspectos relacionados ao e-learning que foram pesquisados, seis obtiveram grau de concordância superior a 70\% (somatório das respostas da opção 3 - Concordo e, da opção 4 - Concordo plenamente) conforme Gráfico 2.

Com referência a esses seis itens, com nível percentual de concordância superior a $70 \%$ (grifados em azul no Gráfico 2), podemos afirmar, no âmbito dessa amostra, que:
1. Apresentação gráfica e interação: para $87 \%$ dos participantes da pesquisa, os programas de treinamento e-learning possuem apresentação gráfica e formas de interação bastante atraentes para o aluno. Essa questão é um grande desafio para as organizações, que necessitam desenvolver metodologias adequadas aos cursos e-learning e, simultaneamente, os cursos também devem possuir uma interface gráfica atraente para o aluno. A parceria 
Gráfico 2: Nível percentual de concordância

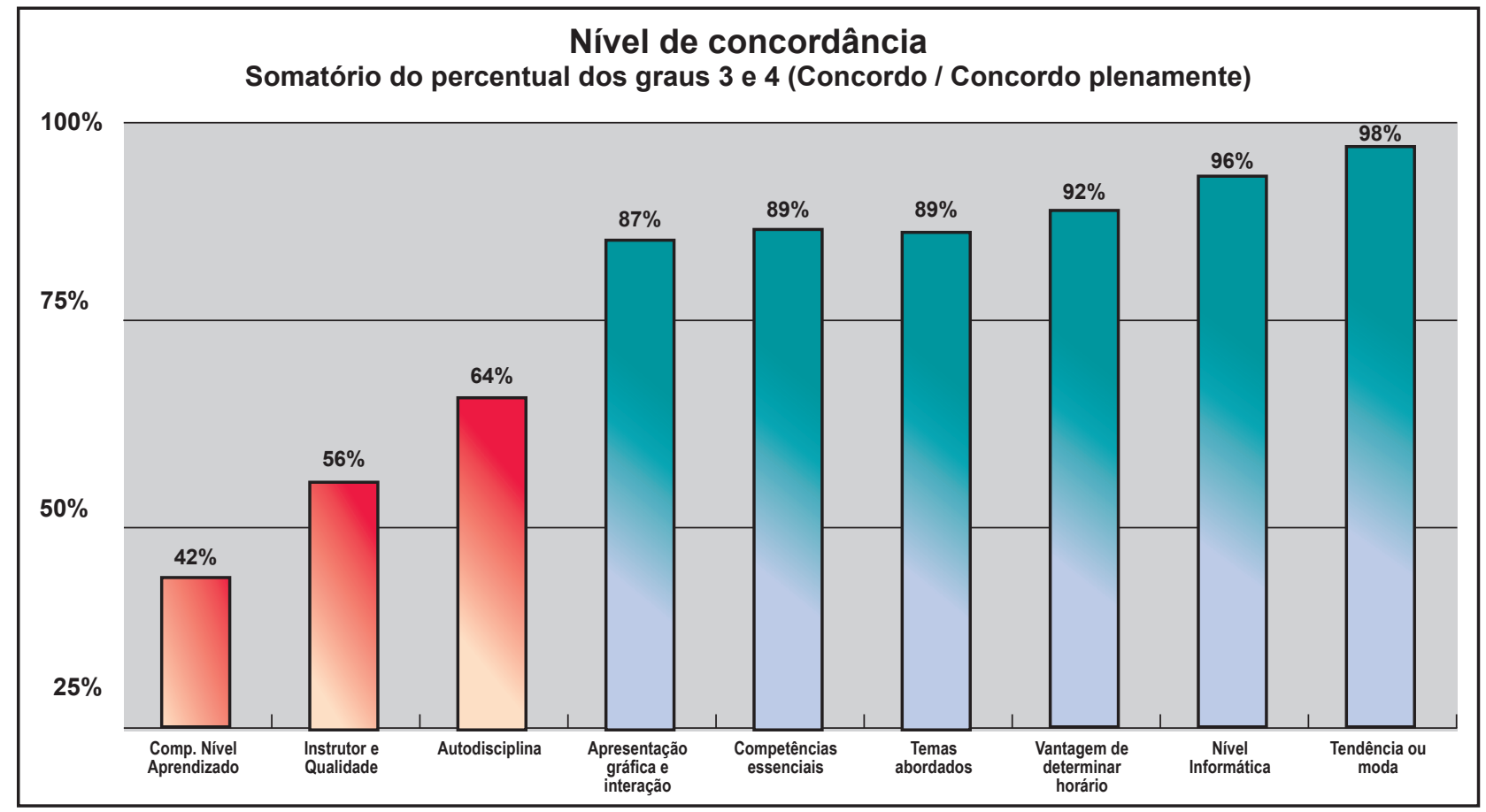

dessa instituição financeira com empresas especializadas em desenvolvimento de cursos e-learning provavelmente contribuiu para o elevado nível de concordância deste item.

2. Competências essenciais: $89 \%$ dos respondentes conseguem identificar de forma clara a relação entre os cursos e-learning $e$ as competências essenciais de sua empresa. Na maioria das empresas que possuem Universidades Corporativas, os cursos e-learning são uma das principais ferramentas de treinamento. Como o alinhamento das UCs com as competências essenciais é um de seus principais objetivos, quando os participantes identificam esta relação; é um indicativo de que esse objetivo está sendo atendido.

3. Temas abordados: para $89 \%$ dos pesquisados, os temas abordados nos cursos de e-learning são atraentes e possuem aplicabilidade prática para o seu ambiente de trabalho. Como na empresa pesquisada são oferecidos atualmente diversos cursos e-learning, abrangendo as áreas comportamental, técnica e de informática, esse resultado é um indicativo de que a ferramenta e-learning não tem restrições para ser utilizada nos principais tipos de treinamento existentes.
4. Vantagens de determinar horário: $92 \%$ dos pesquisados consideram uma grande vantagem do curso e-learning, em relação aos cursos presenciais, o fato de poder determinar o horário de estudo. Esse resultado confirma, no âmbito desta amostra, a questão amplamente divulgada na literatura de que uma das principais vantagens do curso e-learning é não ter de cumprir horários previamente definidos. Ações de divulgação de cursos e-learning podem explorar esse ponto para seu público-alvo.

5. Nível de informática: para $96 \%$ dos participantes da pesquisa, o nível de conhecimento de informática que eles possuem os possibilita utilizar plenamente os recursos técnicos que envolvem o treinamento e-learning, ou seja, aspectos de acesso, navegação, multimídia, participação em chats, interrupção e retomada do curso etc, não representam um empecilho para participação em cursos e-learning. Essa questão é importante para a investigação dos demais pontos da pesquisa, pois deficiências no aspecto de informática podem contaminar a percepção dos pesquisados sobre os demais itens do questionário.

6. Moda ou tendência: para $98 \%$ dos pesquisados, o e-learning é uma tendência que veio para 
ficar, e acreditam que cada vez mais as empresas irão investir nessa ferramenta para realização de cursos. Estes números demonstram que os pesquisados não veem o e-learning como uma moda passageira; ao contrário, acreditam na sua perenidade, o que pode contribuir para aumentar sua credibilidade dentro das organizações.

Os três itens que apresentaram níveis percentuais de concordância (somatório das frequências dos graus 3- Concordo e 4- Concordo plenamente) abaixo de $70 \%$ (grifados em vermelho no Gráfico 2), também foram os únicos que obtiveram médias abaixo de 3,0 (equivalente ao grau "Concordo" na escala Likert estabelecida), conforme Gráfico 3.

Com referência a esses três itens, com níveis de concordância inferiores a 3 (grifados em vermelho no gráfico), podemos afirmar, no âmbito dessa amostra, que:

1. Comparação do nível de aprendizado: na média das respostas, os pesquisados não concordam que o treinamento e-learning é capaz de proporcionar o mesmo nível de aprendizagem do que um curso presencial.

Gráfico 3: Nível de concordância

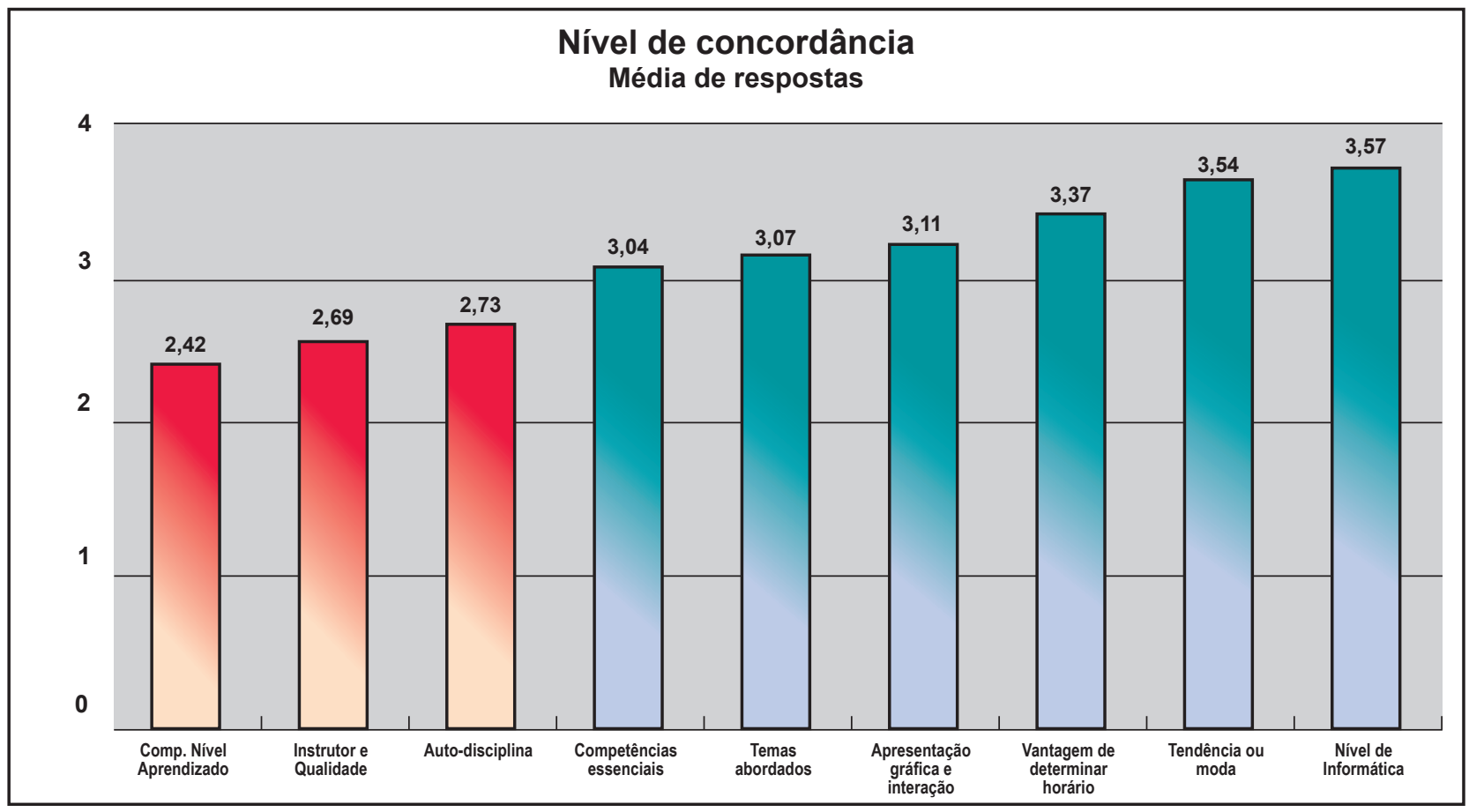

2. Ausência de instrutor: os participantes da pesquisa, na média, consideram que a ausência de um instrutor durante uma atividade de treinamento prejudica a qualidade do aprendizado.

3. Autodisciplina: os correspondentes, na média, não possuem disciplina para realizar as tarefas previstas, ou seja, não conseguem planejar e realizar suas atividades de treinamento via e-learning de forma satisfatória.

\section{Discussão e considerações finais}

Apesar de ser um tema novo em termos empresariais e acadêmicos, o e-learning já possui uma ampla revisão bibliográfica e também diversos exemplos organizacionais que possibilitam analisar sua filosofia, sua estruturação, seu modo de funcionamento, e também questões que ainda necessitam de uma reflexão aprofundada.

A aceitação da metodologia e-learning na pesquisa exploratória realizada é bastante positiva por parte dos alunos nos aspectos ligados à facilidade para utilização dos recursos de informática, autodisciplina para realizar o curso, apresentação gráfica/nível de interação dos cursos, vantagem de determinar o horário de estudo, relação entre os cursos e-learning e as competências essenciais, aplicabilidade dos temas abordados e a percepção de que o e-learning é uma tendência. A pesquisa aponta para a necessidade de novos estudos que analisem a diferença de nível de aprendizagem entre cursos e-learning e cursos presenciais, bem 
como identificar formas de compensar a ausência de contato permanente dos alunos com os instrutores no decorrer do curso e formas de estimular maior discplina para realização das atividades.

Novos estudos serão desenvolvidos visando comparar os resultados dessa pesquisa com os dados extraídos de pesquisa semelhante realizada na SulAmérica Seguros, bem como para aprofundamento de questões relacionadas:

- A diferença de nível de aprendizado entre um curso e-learning e presencial.

- Como suprir a necessidade de presença física do instrutor em sala de aula.

- Fatores que influenciam a disciplina para realização das atividades do e-learning.

A pesquisa será também ampliada por meio do uso de outras ferramentas além dos questionários. Uma observação participante seria útil no sentido de averiguar as transformações na disposição dos alunos para aprender e verificar os tipos de mudanças de atitudes que estão ocorrendo em decorrência da popularização desta nova modalidade de ensino.

Em se tratando de uma modalidade que requer uma postura mais autodidata, autônoma e, portanto, empreendedora, há que se considerar que a EAD coloca um grande desafio às organizações que querem utilizar-se dessa modalidade de ensino. A implementação de programas de EAD, como já foi dito, requer, antes de tudo, um planejamento bem-feito a fim de que resultados positivos possam ser alcançados.

Tal planejamento deve necessariamente levar em consideração a ruptura no modelo de aprendizagem através do qual o futuro aluno foi socializado, em geral o ensino bancário em que o professor deposita seu conhecimento nas cabeças dos alunos (FREIRE, 1996).

Os desafios que se nos colocam pela sociedade do conhecimento do novo século requerem, sobretudo, profissionais que sejam capazes de aprender a resolver problemas para os quais as soluções ainda estão por construir. Daí a necessidade de profissionais pró-ativos, autodidatas, empreendedores e, sobretudo, aventureiros.

Para tanto, é preemente a necessidade de aprender a aprender, aprender a descobrir, aprender a se aventurar pelas avenidas do desconhecido, da complexidade e do desafio de inovar. A EAD não é a nova panaceia capaz de resolver todos os problemas vindouros, mas pode ter importante papel ao incentivar o espírito da autonomia. 


\section{Referências bibliográficas}

DUBLIN, L. In the land of e-learning myths: a knight's tale. In ROSENBERG, Mark J. Beyond e-learning: approaches and technologies to enhance organizational knowledge, learning, and performance. San Francisco: Pfeiffer, 2006.

EBOLI, M. Educação corporativa no Brasil: da teoria à prática. ENCONTRO DA ASSOCIAÇÃO NACIONAL DOS PROGRAMAS DE PÓS-GRADUAÇÃO EM ADMINISTRAÇÃO, 2004, Curitiba. Anais. Curitiba: ANPAD, 2004a. [CD_ROM]

EBOLI, M. Educação corporativa no Brasil: mitos e verdades. São Paulo: Gente, 2004b.

EBOLI, M. O papel das lideranças no êxito de um sistema de educação corporativa. Revista de Administração de Empresas, São Paulo, v. 45, n. 4, out./dez., 2005.

FARIAS, G. O que é educação a distância? Mar. 2004. Disponível em: <http://portal.webaula.com. br/artigo.aspx?sm $=$ artigos \&codartigo $=6>$. Acesso em: 07 fev. 2007.

FERRAZ, C. M. Universidades corporativas. In BOOG, Madalena; BOOG, Gustavo. (Org.). Manual de Gestão de Pessoas. São Paulo: Gente, 2002. v. 2.

FERREIRA, J. R.; BENETTI, G. (Coord.). O futuro da indústria: educação corporativa: reflexões e práticas. Brasília: MDIC/STI - IEL, 2006

FILHO, D. M.; DIAS, D. Modernização organizacional e práticas inovadoras de treinamento: um modelo relacional de estudo com profissionais de organizações mineiras. ENCONTRO DA ASSOCIAÇÃO NACIONAL DOS PROGRAMAS DE PÓS-GRADUAÇÃO EM ADMINISTRAÇÃO, 2006, Salvador. Anais. Salvador: ANPAD, 2006. [CD_ROM].

FLEURY, M. T. Aprendizagem e gestão do conhecimento. In: FLEURY, Maria Tereza. As pessoas na organização. São Paulo: Gente, 2002.
FLEURY, M. T.; JACOBSOHN. A contribuição do e-learning no desenvolvimento de competências do administrador. ENCONTRO DA ASSOCIAÇÃO NACIONAL DOS PROGRAMAS DE PÓS-GRADUAÇÃO EM ADMINISTRAÇÃO, 2003, Atibaia. Anais. Atibaia: ANPAD, 2003. [CD_ROM].

FREIRE, P. Pedagogia da autonomia: saberes necessários à prática educativa. São Paulo: Paz e Terra, 1996.

LAGO, F; SANTOS, C. Dossiê e-learning. Revista Melhor, São Paulo, n. 215, out. 2005.

LEMOS, D. C. Educação corporativa: pesquisa de soluções em e-learning e modelos de universidades corporativas. 2003. Dissertação (Mestrado em Engenharia de Produção) - Programa de Pós-Graduação em Engenharia de Produção, Universidade Federal de Santa Catarina, Florianópolis, 2003.

LIÇÕES aprendidas. Revista $T \& D$. São Paulo, ano 13, n. 139, 2005.

MEISTER, J. C. Educação corporativa: a gestão do capital intelectual através das universidades corporativas. São Paulo: Makron Books, 1999.

MEISTER, J. C. Corporate universities: the new pionners of management education. Harvard Management Update, Boston, Harvard Business School Publishing, out, 1998.

PILLA, B.; NAKAYAMA, M.; BINOTTO, E. Práticas de e-learning em empresas: uma pesquisa exploratória na Austrália e no Brasil. ENCONTRO DA ASSOCIAÇÃO NACIONAL DOS PROGRAMAS DE PÓS-GRADUAÇÃO EM ADMINISTRAÇÃO, 2006, Salvador. Anais... Salvador: ANPAD, 2006. v.

PRAHALAD, C. K.; HAMEL, G. Competence of the corporation. Harvard Business Review, Boston, mai-jun, 1990.

ROSENBERG, M. J. Beyond e-learning: approaches and technologies to enhance organizational knowledge, learning, and performance. San Francisco: Pfeiffer, 2006. 
SOELTL, F. A. E-learning. In BOOG, Madalena; BOOG, Gustavo. (Org.). Manual de Gestão de Pessoas. São Paulo: Gente, 2002. v. 2.

YIN. R. Estudo de caso: planejamento e métodos. 3. ed. Porto Alegre: Bookman, 2005.

ZERBINI, T.; NASCIMENTO, S.; MENESES, P. et al. Percepções sobre a educação a distância: limitações $e$ restrições à implantação da UC do BACEN. ENCONTRO DA ASSOCIAÇÃO NACIONAL DOS PROGRAMAS DE PÓS-GRADUAÇÃO EM ADMINISTRAÇÃO, 2006, Salvador. Anais. Salvador: ANPAD, 2006. [CD_ ROM]. 